\title{
The International Jewish Youth Camp at Szarvas
}

\author{
History, impact and future
}

\author{
Mina Pasajlic
}

DOI: $10.30752 /$ nj.86055

\begin{abstract}
Aвstract • The JDC-Lauder International Jewish Youth Camp at Szarvas is perceived today as the single most important Jewish outreach and educational programme in Central and Eastern Europe; it is a key symbol for Eastern European Jewry. This paper emphasises the importance of the Szarvas camp, located some I7o km south-east of Budapest in Hungary, and its impact on the Jewish identity of the Central and Eastern European participants, and by extension on their families and communities. It focuses on the camp's history and uniqueness, and includes a personal experience on the part of the author, who has participated in the camp and today works as its programme director. It also presents information collected from those who have experienced the impact of the camp on themselves.
\end{abstract}

\section{The history of the Szarvas camp}

The origin of the Szarvas camp is embedded in the history of Jewish life in Central and Eastern Europe. Before 1989, the official Communist policy was to eradicate religion and religious identity from society. The opportunities for Jewish education were very limited, and almost non-existent for young Jews to learn more about their identity.

The fall of the Berlin wall in 1989 marked a turning point in the revival of Jewish life in Central and Eastern Europe. After 1989, it became a matter of choice whether and how to rediscover and develop Jewish identity, and many young Jews sought opportunities to explore their Jewish roots and reclaim their Jewishness. One of the institutions that helped to reconstruct Jewish life in the region was the 'JOINT' or American Jewish Joint Distribution Committee (JDC). In I990 the JDC partnered with the Ronald S. Lauder Foundation and opened the JDC-Lauder International Jewish Youth Camp - the Szarvas camp.

In the early years only a few countries participated in the camp - mainly Hungary, Czechoslovakia and countries of the former Yugoslavia. Over the decades the camp has significantly developed and the number of participants has increased. In recent years, it has hosted around I6oo children from more than forty communities in over twenty-five countries each summer. These include Hungary, the former Yugoslavia, Bulgaria, Romania, Turkey, Albania, the Czech Republic, Slovakia, Poland, Russia, Ukraine, Belorus, the Baltic countries, Moldova, Germany, USA, Israel and India.

\section{The camp's goals}

The camp was built with the straightforward goal of providing Jewish education and experiences for those from Central and Eastern 
Europe. The overarching aim was to create a community that nurtures and strengthens personal Jewish identity and community development based on entertaining education, in a safe, encouraging and varied environment. The camp tries to make the Judaism it represents accepting and open for everyone. It helps camp participants to form and live their own Jewish identity and to find their own personal connection to the concept and the reality of Jewish community.

There are several aspects that are important for both the campers and the staff: to be an active and positive part of the community; to be open to the world, to Judaism and to their environment; to learn about Jewish culture and tradition; to experience how it feels to be part of a group; to open up and get to know themselves both as individuals and as Jews; to learn to respect themselves and others; to push themselves out of their comfort zone in order to learn and develop and to make new friends and deepen their already existing relationships.

The Szarvas camp attempts to combine the building of the community with personal development. Campers experience the camp and its Jewish and general themes through creative and interesting adventures and programmes. Programmes about Jewish traditions and values are communicated interactively, through discussions and debates, exercises and games, and are based around the principle of individual free choice. For many participants, the two-week-long stay at the camp is their first real encounter with Jewish traditions and has the potential to be a truly life-changing experience.

One of the unique aspects of the camp is its international character. It brings together participants with a variety of linguistic and cultural backgrounds, mentalities and characters, which together create a unique international mosaic. This creates a feeling of global Jewish identity. The camp sends participants home equipped with knowledge, pride and joy in Judaism, and a sense of belonging to a global community.

\section{The impact of the Szarvas camp}

The Szarvas camp encourages and enables participants to become more active members of their Jewish communities. The survey, The Camping Experience: The Impact of JDC Jewish Summer Camps on Eastern European Jerws, conducted by the JDC International Center for Community Development (JDC-ICCD) in 20I2-I3 indicates that in many ways, those who went to summer camps as youth expressed stronger Jewish identities as adults'. The survey shows that 64 per cent of the interviewees marked their Jewish identity as 'strong' (on a scale from I to Io, they gave 8 or higher). The same survey points out the summer camps also had a big impact on those children living on the periphery of Jewish communities. Those who have attended Jewish summer camps have 'had more positive attitudes on a range of issues compared to non-campers. It may be posited for this group that the camp had a large impact. They gave a higher assessment of the intensity of their current Jewish identity, despite the fact that they came from the same type of family background.' One of the conclusions of this survey was the following: 'While caution must be taken in ascribing cause and effect, there seems to be clear correlation between summer-camp attendance and current Jewish identity, particularly notable among those of weak Jewish backgrounds.'

The scale of impact is best understood by bearing in mind the historical and political context of the Communist past, in which the parents and grandparents of participants were brought up. As already mentioned, the official Communist policy of atheism, and targeting of Jews, seriously eroded their Jewishness and Jewish identities. On returning to their homes, those attending the Szarvas camp expressed a 


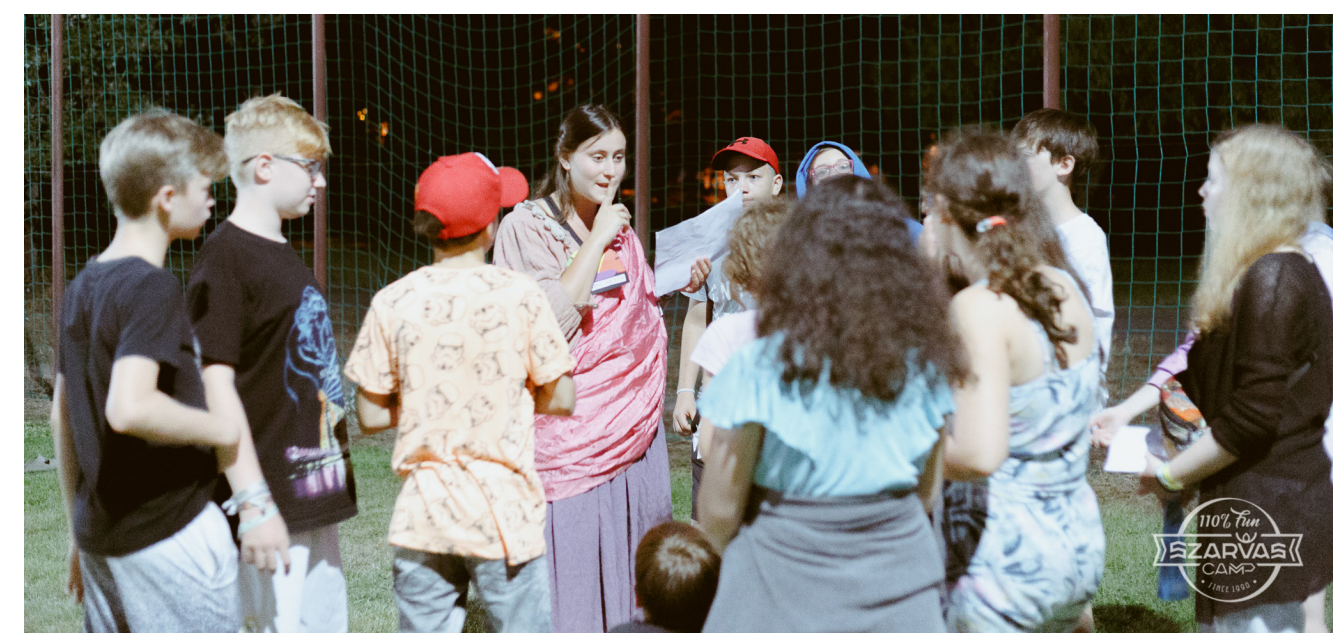

Evening programme.

Campers during one of the camp's evening programmes, learning about biblical personalities.

desire to be part of Jewish communities and to participate in programmes and activities for children and youngsters. In fact, even their families 'went back' to their Jewish communities and started rediscovering their Jewish identity. The process of the rebuilding of the Jewish communities and life in Central and Eastern Europe was thus twofold: on the one hand, the participants started to explore their Jewishness, and on the other hand, the parents, precisely because of their children, reconnected with their abandoned identity.

The impact of the camp on the participants is evident in the following examples.

Monika, I5 (Bulgaria):

I've met so many new people and made a lot of my best friends at Szarvas camp. My life has changed completely because of the people here. To learn about Judaism from people from around the world is amazing. We have different ways of interpreting our Judaism and I think it's really cool. Szarvas has changed the way that I view Judaism. I am so excited to enter the training programme for counsellors, to learn how to work in a team, become more responsible, and to be leader for younger kids.
Daniel, I4 (Russia):

Shabbat was the best day of the camp. I've learned a lot. I carried the Torah from the ark for the first time in my life. I've seen it done before, but I've never held the Torah myself until now.

Rotem, I4 (Romania):

This camp allows me the freedom to be who I want, to do what I like, and to go for it. The community accepts me with open arms. I hope to become a counsellor at Szarvas some day. I want to give younger children the same positive experience I enjoyed.

The Szarvas camp has also had a great impact on its staff. Many of those who today lead the camp began as seven- or eight-year-old first-time campers, and went on to spend all of their summers in Szarvas up to the age of eighteen, gaining more and more new knowledge, new skills and new experiences. They experienced how it feels to be part of an open, welcoming Jewish community and, with time, they took on a more active role and greater 


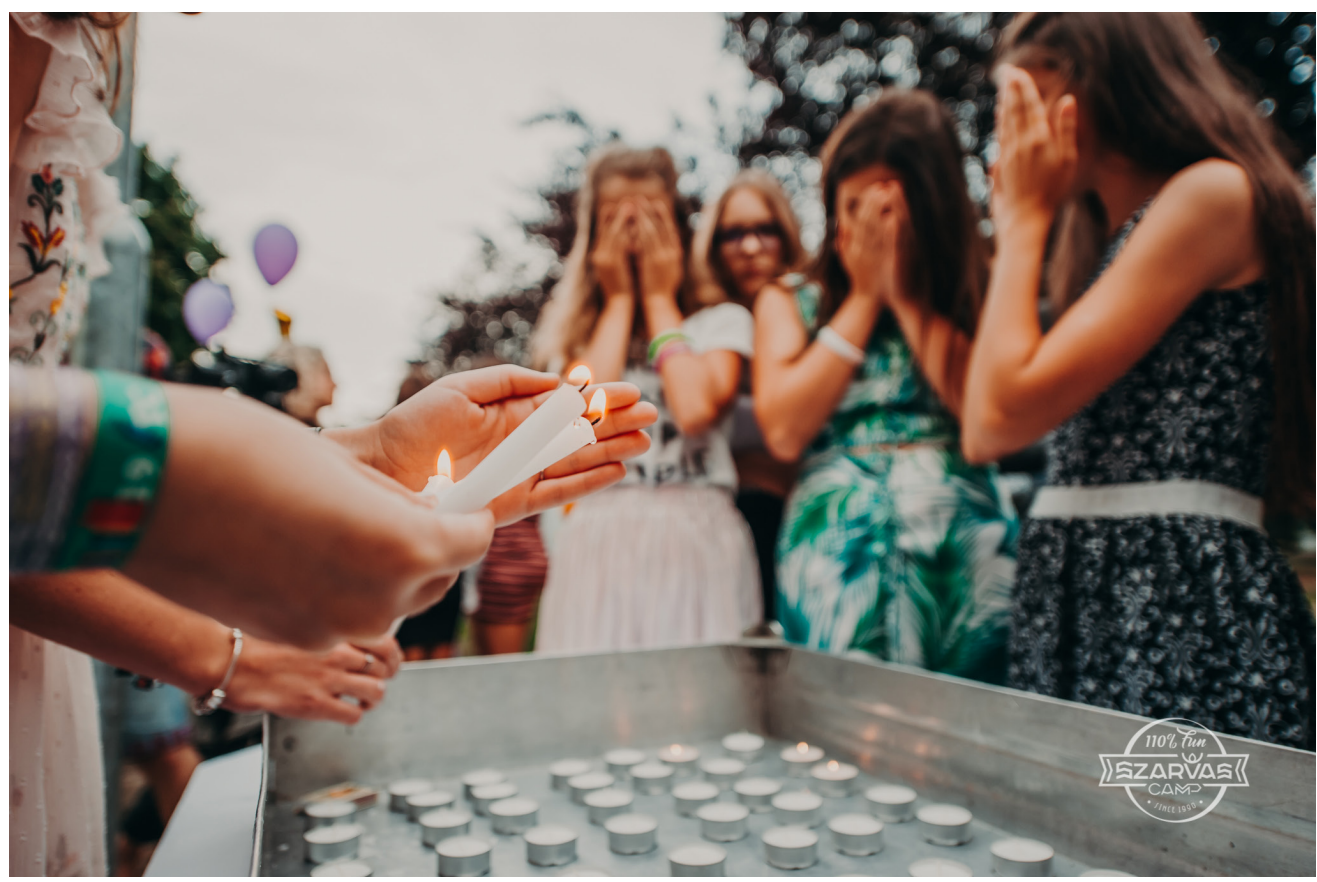

Shabbat.

Campers and staff lighting candles before the Shabbat service

responsibility in the camp's life. Many of them became madrichim (counsellors), members of staff and unit heads (senior educational staff members). Today, they are the ones who prepare, lead and create the activities and programmes that they themselves earlier practised with so much love and joy. They are the ones now creating the Szarvas camp experience for the next generations.

I myself am an example of this phenomenon. My first time at the camp was back in the early I 990 os when I was eight or nine years old. Growing up, I have spent my summers at Szarvas as a camper. The very powerful camp experience led me to start attending children's activities in my home Jewish community of Belgrade (Serbia). At the age of eighteen I became a madricha (a counsellor) and a few years later a unit head. Today I work as the programme director for the camp. The Szarvas camp was my greatest formative Jewish experience while growing up, and it had a strong impact on me. It pushed me to explore my
Judaism and my identity, to learn more, to challenge myself in different ways and to be curious. My passion for Judaism and Jewish experiential education has been growing since then. This past summer was my twenty-fifth summer at camp. It is very clear to me that the Szarvas camp had, and continues to have, a unique impact on who I am today.

Similarly, alumni of Szarvas camp have become leaders and professionals in their own Jewish communities, leading local Jewish summer camps or Jewish community centres, or opening Jewish schools, and so much more. Two alumni from Croatia opened the Jewish school in Zagreb sixteen years ago; two alumni from Bulgaria are leaders in the Jewish community of Sofia, and were involved in opening a new Jewish school last year; an alumna from Poland is a director of JCC Warsaw; an alumna from Serbia is an executive director of the European Union of Jewish Students; an alumna from Macedonia is today a JDC employee running empowerment programmes for young adults 


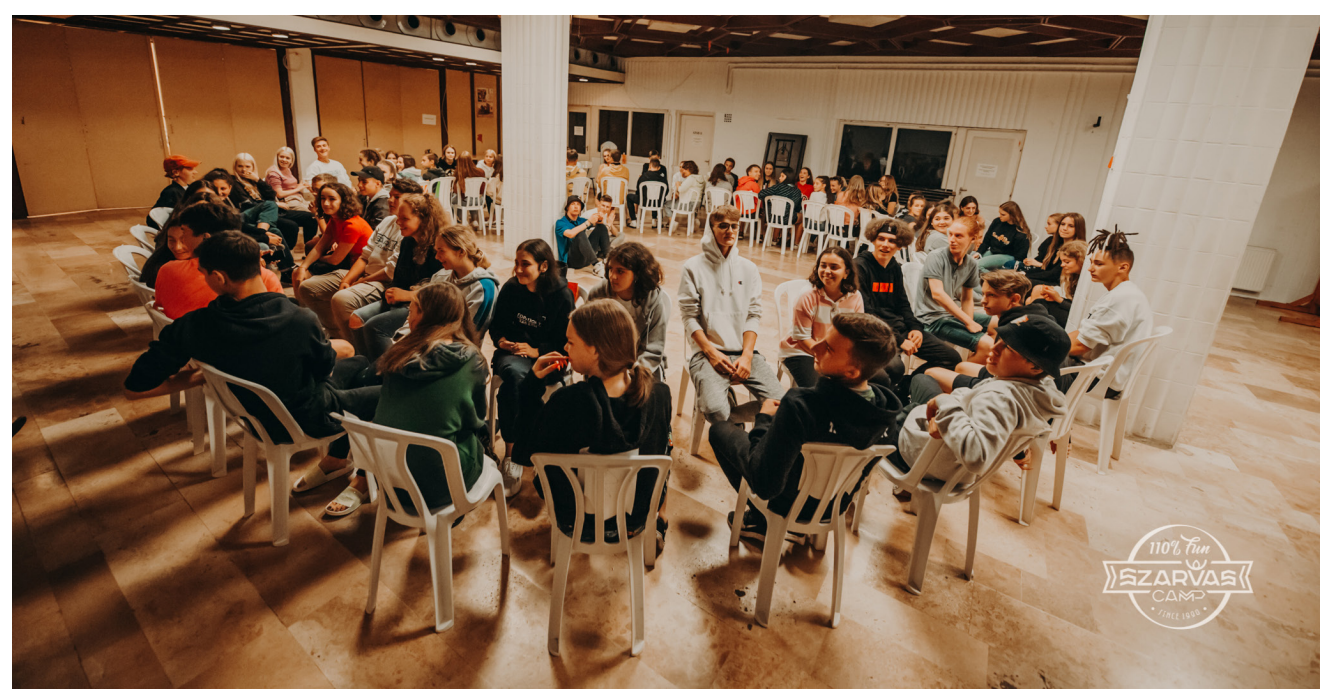

Discussion.

Campers during one of the camp's programmes, listening to a question they need to discuss

in Europe. Some further examples represent the impact of the Szarvas camp:

Sonja Vilicic, Szarvas camp alumna; cofounder and executive director of NGO Haver Srbija (Serbia):

Like many Jews in my part of the world, I started to connect to Judaism and the Jewish community through the Szarvas summer camp. It was the first and, for many years, the only place which provided me with Jewish education and it was the place where I explored and developed my Jewish identity. I grew up in this camp - as a person, as a Jew and as a leader. Szarvas helped me to be more human, to care for others, to be curious and creative, to take a risk and dive into the unknown. It connected me to and made me care about the global Jewish community, provided me with friends and skills for life and helped me find my purpose as a Jew, as an educator, as an activist and as a leader. I am who I am because of Szarvas.

Jutka Lubeck, Szarvas camp coordinator (Hungary):
I don't know where I would be without Szarvas. I don't think there would be another place that would have given me these limitless borders to become the person that I am now. Szarvas is not just a summer camp, it's a place where the Jewish future is being built.

Rebeka Mucheva, Szarvas camp unit head; director of Bnei Brit Youth Organisation, Eastern Europe (Macedonia):

When I first went to Szarvas, fifteen years ago, I discovered that there is a much bigger Jewish community than the one in my home city that had only 250 members. I met some of my nowadays best friends and colleagues there, completely unaware of the life-changing experience I had had. Szarvas camp has been a part of my life for as long as I can remember and it has taught me invaluable lessons - from singing Jewish songs to being a leader and a role model. It motivated me to be curious about Judaism, to learn and to teach, to challenge myself and to aspire to be the best Jewish leader that I can be. 
Agata Rakowiecka, Szarvas camp alumna; director of JCC Warsaw (Poland):

\section{I went to Szarvas camp at a critical} moment in my life. Like every teenager I was going through the phase of asking myself crucial questions, such as: Who am I? What is important to me? What are my skills and interests? The Szarvas experience shaped my answers. I have discovered the power of a pluralistic community, which elevates the individual and gives a sense of belonging. I have been empowered to shape my reality and inspired to seek development and creativity in Judaism. Szarvas gave me lifelong friendships and to this day I appreciate the impact it had on me and my colleagues and how it continues to impact the next generations.

Maya Cimesa Samokovlija, Szarvas camp alumna; coordinator for Eastern Europe and Eurasia, World Jewish Congress (Croatia):

I can say that because of this camp and the influence and impact that it had on me, together with my friend and the support of Jewish community, sixteen years ago we opened the Jewish elementary school in Zagreb, Croatia.

Daria Cotorobai, Szarvas camp unit head; event manager of JCC Kishinev (Moldova):

Being a Jew in the former Soviet Union area is not so simple. Global projects such as the Szarvas camp create strong connections between Jewish youth around the world. I'm happy to have been part of the Szarvas camp for the last six years. I can see how teens from my country, Moldova, are inspired by other teens and Jewish leaders from the around the world. This possibility is a motivation for them to take an active part in community today and to become future Jewish leaders. For me as for professional worker in JCC this is very meaningful and powerful. I'm also very thankful to Szarvas for my personal growth as a leader, educator and role model. This is the unique experience which you couldn't find anywhere else.

Tinatin Ciciszwili, Szarvas camp unit head; co-director of Jewish summer camp 'Atid' (Poland):

I am glad to be a part of the Szarvas camp and the journey it took me through. Thanks to all the educational and social experiences that the camp provided, I was able to build and shape my Jewish identity and understand how important it is to me, not only as an individual but as a leader as well. It all allowed me to see the needs of my community and react to them. I am able to bring the new knowledge from the camp back to my community. In that context, I am able to give something back by contributing to the education of future generations, and to help strengthen the community. For me, the Szarvas camp gives an amazing opportunity to see European communities and their members develop, get involved and take responsibility, as the children grow into leaders capable of addressing their communities' needs.

Hana Salom, Szarvas camp unit head; regional manager at JFuture (Serbia):
Without Szarvas, I would have nothing to connect me to Judaism. My experiences at Szarvas motivated me to study and to understand things on a deeper level, so that I can explain it to other kids.

Zsuzsa Fritz, Szarvas camp educational consultant (Hungary): 
I'm really convinced that Szarvas is the best thing that ever happened to Europe, because it brings this positive Jewish experience which these communities in Europe really need. Today, in most of these communities, the people who run the show, the people who do the youth programming, run the clubs, they are Szarvas graduates.

The people who invent new Jewish stuff, modern Judaism in these communities, are Szarvas people.

The camp itself is also active outside the summer season, with its empowerment programmes, such as leadership training for madrichim and camp staff, collaborations and cooperation with various Jewish communities and organisations and much more.

Thirty years since its opening, the value and importance of Szarvas camp has not decreased. There is still the same need to help young Jews to find, develop and strengthen their Jewish identity, to show them the many ways to be Jewish and lead a Jewish life and to nurture their Jewish education and be a support on their Jewish journey. The Szarvas camp continues to do all of these things. Indeed, even amidst the coronavirus pandemic and the cancellation of the 2020 summer session, the Szarvas camp is working towards offering educational and Jewish identity-shaping resources in the digital space and its alumni are central to helping Jewish communities cope with the impact of the health crisis, from social service delivery to the provision of critically-needed community connection and Jewish educational content online.

\section{Bibliography}

Cohen, Erik H., 2013. The Camping Experience: The Impact of JDCJewish Summer Camps on Eastern European Jerws (London, JDC International Center for Community Development) <https:// archive.jpr.org.uk/object-eur104>

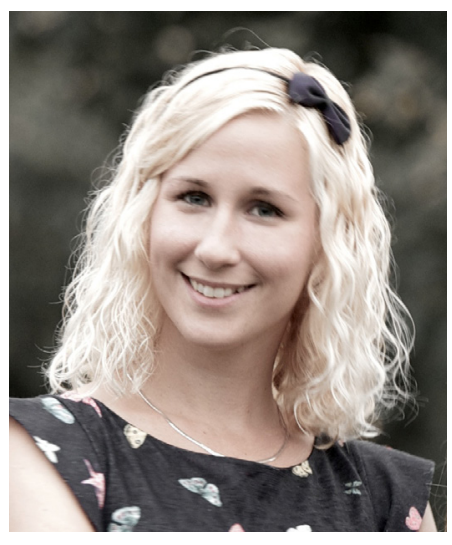

Mina Pasajlic was born and raised in Belgrade, Serbia. She has been involved in informal Jewish education since she was 17. While working in her own local Jewish Community, Mina was in charge of organising family and children events and seminars and various other projects. Since December 2010, Mina works for JDC as a programme director of Szarvas International Jewish Summer Camp in Hungary. In January 2013 Mina co-founded the NGO Haver Serbia with a colleague, where she works at the project 'Education=Tolerance' - bringing workshops on Jewish culture and tradition, discrimination and tolerance, and Holocaust education to the public schools in Serbia. In the year 2015/2016 Mina spent 8 months studying Jewish studies in Stockholm (Sweden) at Paideia Institute for Jewish Studies. In the year 2018/2019 Mina spent a year learning at Pardes Institute of Jewish Studies in Jerusalem, as part of the Pardes Experiential Educators Program. Mina is still involved in various educational projects in Jewish community of Belgrade and Serbia. 